\title{
ELEP Medical Commission
}

The Medical Commission of ELEP (Association of European Leprosy Organizations), composed of Drs. L. P. Aujoulat, S. G. Browne, Fr. Hemerijckx and Fr. Wegener, met in Brussels on 5 November, 1968, to discuss the medical aspects of diverse projects in which memberorganizations are interested. Thanks to the numerous official and unofficial contacts that the members enjoy in their own countries and abroad, it is possible to make the influence of the voluntary agencies felt in leprosy control schemes in many lands. Contact is maintained with W.H.O. and has been initiated with O.C.E.A.C., the Commission concerned with endemic diseases in the French-speaking countries of Africa.

An interim report on an epidemiological survey of leprosy in Morocco was received, and up-to-date news of the Adzopé Project (in the Ivory Coast) was given by Dr. Aujoulat.

Prospects for the creation of a Professorial chair of Leprology at the University of Dakar (Senegal) were welcomed, especially as it is hoped that the title-holder would be able to spend part of every year lecturing to Frenchspeaking medical students at the different medical schools in West and Central Africa, and include visits to the A.L.E.R.T. Project in Addis Ababa.

The ELEP-sponsored Leprosy Control Project at Dharmapuri (India) is now well under way. Dr. I. A. Susman has appointed paramedical staff and begun preliminary surveys of the area involved.

The Medical Commission of ELEP is concerned that medical priorities should be respected as far as possible in schemes sponsored either jointly or separately by the memberorganizations, while admitting that in some circumstances social and non-medical considerations may be equally important. The channelling into effective leprosy control work of moneys raised by voluntary organizations appealing to the general public often raises delicate questions where the emotional factor may conflict with long-term anti-leprosy strategy.

S. G. Browne

\section{G 30320 or B 663 -Lampren (Geigy)}

Of the many drugs investigated for their activity in leprosy of recent years, one of the most promising is B 663. This drug is one of a long series of rimino-phenaziné derivatives synthesized in the laboratories of the Irish Medical Research Council in Dublin. Its use in leprosy has been the subject of numerous publications, the first of which appeared in the pages of Leprosy Review some 7 years ago.

A slightly edited verbatim report of a Symposium on B 663, which was organized to precede the recent International Leprosy Congress, appears on pages 21 to 48 in this issue. 